\title{
The Effect of Intra-Articular Meperidine and Bupivacaine $0.5 \%$ on Postoperative Pain of Arthroscopic Knee Surgery; a Randomized Double Blind Clinical Trial
}

\author{
Farnad Imani ${ }^{1,2}$; Saeidreza Entezary ${ }^{2}$; Mohammad Razi ${ }^{3}$; Ali Akbar Jafarian ${ }^{2}$; Fardin \\ Yousefshahi ${ }^{4}$; Hasan Etemadi ${ }^{5,} ;$ Saeid Safari ${ }^{2}$ \\ ${ }^{1}$ Pain Research Center, Iran University of Medical Sciences, Tehran, Iran \\ 2 Department of Anesthesiology and Pain Medicine, Rasoul Akram Medical Center, Iran University of Medical Sciences, Tehran, Iran \\ 3 Department of Orthopedics Surgery, Rasoul Akram Medical Center, Iran University of Medical Sciences, Tehran, Iran \\ ${ }_{5}^{4}$ Department of Anesthesiology, Tehran University of Medical Sciences, Iran \\ 5 Department of Anesthesiology, Hazrat Fatemeh Medical Center, Iran University of Medical Sciences, Tehran, Iran \\ ${ }^{*}$ Corresponding author: Hasan Etemadi, Department of Anesthesiology, Hazrat Fatemeh Medical Center, Iran University of Medical Sciences, Tehran, Iran. Tel: +989121029930, E-mail: \\ etemadi.h@yahoo.com
}

Received: January 8, 2015; Revised: February 3, 2015; Accepted: February 5, 2015

\begin{abstract}
Background:Arthroscopic knee surgeries have a painful postoperative course, which often necessitates acute pain management. Among different analgesia techniques, Intra-articular injection is the technique of choice for many pain specialists, based on its confined effect to the surgical site (knee), lack of systemic effects and promotion of safe early ambulation.

Objectives: The aim of this study was to compare analgesic effects of intra-articular meperidine, bupivacaine $0.5 \%$ or their combination after knee arthroscopic surgery.

Patients and Methods: Sixty ASA class I-II patients' candidates for arthroscopy knee surgery enrolled in a randomized double blind study to receive either $20 \mathrm{~mL}$ of bupivacaine $0.5 \% ; 100 \mathrm{mg}$ meperidine (diluted in normal saline) or bupivacaine $0.5 \%$ along with $100 \mathrm{mg}$ meperidine. A written informed consent was obtained from all patients. Postoperative analgesia duration, VAS at 2, 6,12 and 24 hours, the first analgesic request time, total fentanyl consumption in first 24 hours, patients' satisfaction and adverse effects were recorded.

Results: The bupivacaine-meperidine group had better duration of postoperative analgesia $(\mathrm{P}=0.001)$, latter first analgesic request $(\mathrm{P} \leq$ 0.001), lower total fentanyl consumption in first 24 hours after the operation $(P=0.001)$, less mean VAS at 2 hours $(P=0.001)$ and more patients' overall satisfaction $(\mathrm{P}=0.01)$ compared with each medication alone. VAS at 6,12 and 24 postoperative hours were not different between the groups of study. No adverse effects were observed.

Conclusions: Although postoperative intra-articular meperidine is a better alternative for bupivacaine, their combination could improve their analgesic effects compared with each other alone.
\end{abstract}

Keywords: Intra-Articular Injection; Pain; Meperidine; Bupivacaine

\section{Background}

Pain is an important complication following knee surgeries including knee arthroscopies (1-3). Postoperative pain could disrupt effective immediate physiotherapy, postpone patient's recovery, prolong the period of hospitalization and increase the costs of patient. Continuous epidural analgesia (4), femoral nerve blockade (5), patient-controlled analgesia (PCA) (2) and intra-articular injection of analgesics are various techniques of analgesia to control postoperative knee arthroscopy pain (6-8). Bupivacaine is a local anesthetic administered intraarticularly by some physicians to prevent acute pain in knee surgeries. It has short analgesic duration. To extend its duration of analgesia, bupivacaine has been accompanied by an opioid (e.g. morphine) in some studies, but morphine alone lacks local anesthetic effects and has slow onset of action and highest risk of respiratory depression among opioids (7, 9-12). Meperidine is an opioid with weak local anesthetic property. It has been used in spinal, epidural and caudal analgesia, as well as intravenous regional anesthesia (IVRA) (13-15).

\section{Objectives}

The short duration of intra-articular local anesthetics like bupivacaine is a major limitation to favor it as an effective treatment to overcome more long-lasting pain of arthroscopic surgeries. Weak but long-lasting local and regional analgesic effects of meperidine raised our hopes to find a better effect from bupivacaine-meperidine mixture to control postsurgical knee arthroscopy pain. The aim of this study was to compare clinical effects of $20 \mathrm{~mL}$ intra-articular injection of a solution containing $100 \mathrm{mg}$ meperidine, bupivacaine $0.5 \%$ or their combination after knee arthroscopic surgery to control postoperative pain, analgesic demand and patient satisfaction.

Copyright (C) 2015, Iranian Society of Regional Anesthesia and Pain Medicine(ISRAPM). This is an open-access article distributed under the terms of the Creative Commons Attribution-NonCommercial 4.0 International License (http://creativecommons.org/licenses/by-nc/4.0/) which permits copy and redistribute the material just in noncommercial usages, provided the original work is properly cited. 


\section{Patients and Methods}

After approval of the Medical Ethics Committee of Iran University of Medical Sciences and obtaining written informed consent, 60 adult patients, ASA physical status I-II, undergoing knee arthroscopic surgery were enrolled in this randomized double-blinded study. They were randomly assigned into one of the three groups B, M and BM (20 in each group) according to a computerized block randomization (www.randomizer. org) sequence sheet. All ASA I-II adults who were mentally, socially and psychologically intact, corporative and oriented scheduled for knee arthroscopy in the referral university hospital of Rasoul Medical Center entered the study. Patients with the following conditions were not entered: 1) a severe systemic diseases (e.g. coagulative, convulsive and cardiac disorders), 2) opioid abuse, 3) allergy to local anesthetic or meperidine, 4) consumption of analgesics 24 hours before the operation, 5) bilateral surgeries and 6) presence of any other painful disorder. Exclusion criteria were: 1) patient refusal any time during the study, 2) reoperation before the end of study and 3) postoperative delirium or disorientation. Any excluded case had to be replaced by another matched case according to its randomization sheet grouping. All patients received general anesthesia similarly. Induction of anesthesia was achieved with Propofol $2.5 \mathrm{mg} \cdot \mathrm{kg}^{-1}$ and alfentanil $30 \mu \mathrm{g} . \mathrm{kg}^{-1}$. Endotracheal intubation was facilitated with atracurium 0.6 mg. $\mathrm{kg}^{-1}$. Anesthesia was maintained with inhalation of nitrous oxide (50\%) in oxygen and infusion of propofol $50 \mu \mathrm{g} \cdot \mathrm{kg}^{-1} \cdot \mathrm{min}^{-1}$ and alfentanil $0.5 \mu \mathrm{g} \cdot \mathrm{kg}^{-1} \cdot \mathrm{min}^{-1}$. Patients' vital signs (ECG, heart rate, oxygen saturation and noninvasive arterial blood pressure) were continuously monitored throughout the operation and thereafter until discharge from the recovery room. At the end of the operation, according to the randomization sheet sequence, $20 \mathrm{~mL}$ of one of three intra-articular solutions of study prepared by an anesthesiologist in an unlabeled syringe, was slowly injected in patients' knee joint through arthroscope by the surgeon blinded to the type of medication. These solutions either contained $20 \mathrm{~mL}$ bupivacaine $0.5 \%$ in B group, $100 \mathrm{mg}$ meperidine (diluted in normal saline) in $\mathrm{M}$ group or bupivacaine $0.5 \%$ along with $100 \mathrm{mg}$ meperidine in BM group. Then patients were transferred to recovery room then to ward if no complication occurred over one-hour care. Following complete consciousness and in arrival to the ward, intravenous patient-controlled analgesia (PCA) of fentanyl was set and patients were educated to use that by their nurse. The PCA pump adjusted for bolus dose of $20 \mu \mathrm{g}$ and lockout period of 15 minutes. The PCA device would be disconnected after 24 hours of the operation. Postoperative pain was assessed by a visual analog scale (VAS) ranging from zero (no pain) to 100 (worst imaginable pain) introduced to patients before the surgery. Duration of postoperative analgesia,
VAS at 2, 6, 12 and 24 hours, the first analgesic requirement time, total fentanyl consumption during the first 24 hours, overall patients' satisfaction and adverse effects (respiratory depression, cardiovascular collapse, pruritus, resistant nausea or vomiting) were recorded by an anesthesiologist in acute pain service (APS) who was blinded in the study. Duration of postoperative analgesia was considered as the time after the operation that VAS remained less than 30. Patient presented their satisfaction level about early postoperative pain, objectively as non-, poor, moderate and excellent satisfaction at 24 hours after the operation. Data was recorded in special designed questionnaire.

\subsection{Statistical Analysis}

Statistical analyses were performed by computerized statistical software (SPSS, version 12; SPSS, Chicago, Ill). To ensure the normal distribution of quantitative variables, Kolmogorov-Smirnov test was performed first. Then one-way ANOVA test was applied for variables distributed normally, and if there was a significant difference, Tukey's test was implemented to find out the differences between the two groups. Kruskal-Wallis test was used for variables that did not distribute normally, and in case of significant difference, Mann-Whitney Utest was used to realize the differences between the two groups. Data were presented as means (SEM). The $\chi^{2}$ test or Fisher's exact test was applied for analyzing qualitative variables. P value $<0.05$ was considered statistically significant.

\section{Results}

Sixty patients (20 in each group) were enrolled in this study. Nobody was excluded. Independent characteristic data (including age, gender and weight), as well as duration of operation did not differ between the three groups (Table 1). Table 2 illustrates the study results; duration of postoperative analgesia was more in group $\mathrm{BM}$ than the other two groups $(\mathrm{P}=0.001)$, but group $\mathrm{M}$ was similar to group $B$. The first analgesic requirement time in BM group (300 \pm 38 minutes) was considerably longer than the other two groups and in M group (132 \pm 60 minutes) was longer than that of B group ( $82 \pm 45$ minutes). Furthermore, the total fentanyl consumption in group BM $(307 \pm 52 \mu \mathrm{g})$ was significantly less than the other two; however, in group M (352 $\pm 98 \mu \mathrm{g})$ was lower than group B (382 $\pm 105 \mu \mathrm{g})$, there was a significant difference only between group BM and other groups $(P=0.001)$. While the mean VAS among all the patients was low and at 6,12 and 24 hours no significant difference was observed, the mean VAS in group BM at 2-hour was less $(\mathrm{P}=0.001)$. The patients' satisfaction regarding pain control in group BM was significantly different from the other two groups $(P=0.01)$. No adverse effects were detected. 
Imani F et al.

\begin{tabular}{|c|c|c|c|c|}
\hline & $\begin{array}{l}\text { Group B (Bupivacaine) } \\
\qquad(\mathbf{n}=\mathbf{2 0})\end{array}$ & $\begin{array}{l}\text { Group M (Meperidine) } \\
\qquad(\mathbf{n}=\mathbf{2 0})\end{array}$ & $\begin{array}{l}\text { Group BM (Bupivacaine }+ \\
\text { Meperidine })(\mathbf{n}=\mathbf{2 0})\end{array}$ & P Value \\
\hline Age, $y$ & $25.1 \pm 4.3$ & $29.4 \pm 5.3$ & $31.6 \pm 8$ & 0.12 \\
\hline Gender; male & $13(65)$ & $14(70)$ & $15(75)$ & 0.788 \\
\hline Weight, kg & $67 \pm 8.6$ & $73.5 \pm 8$ & $71 \pm 5.7$ & 0.33 \\
\hline Duration of operation, min & $115 \pm 39$ & $118 \pm 40$ & $114 \pm 33$ & 0.998 \\
\hline \multicolumn{5}{|c|}{$\begin{array}{l}\mathrm{a} \text { Data are given as mean } \pm \text { SEM or number of patient for gender (\%). } \\
\mathrm{b} \text { There were no significant differences. }\end{array}$} \\
\hline \multicolumn{5}{|c|}{ Table 2. Comparison of Clinical Findings a } \\
\hline & $\begin{array}{c}\text { Group B } \\
\text { (Bupivacaine) }\end{array}$ & Group M (Meperidine) & $\begin{array}{c}\text { Group BM (Bupivacaine + } \\
\text { Meperidine) }\end{array}$ & PValue \\
\hline $\begin{array}{l}\text { Duration of postoperative } \\
\text { analgesia }(\text { VAS }<30), \text { min }^{b}\end{array}$ & $51 \pm 34$ & $72 \pm 40$ & $211 \pm 51$ & 0.001 \\
\hline \multicolumn{5}{|l|}{ VAS at hours } \\
\hline $2^{\text {nd b }}$ & $21 \pm 6$ & $23 \pm 7$ & $15 \pm 5$ & 0.001 \\
\hline 6 th & $20 \pm 8$ & $22 \pm 6$ & $19 \pm 7$ & 0.348 \\
\hline 12 th & $20 \pm 8$ & $25 \pm 9$ & $20 \pm 9$ & 0.176 \\
\hline 24th & $20 \pm 6$ & $21 \pm 7$ & $19 \pm 6$ & 0.285 \\
\hline $\begin{array}{l}\text { The first analgesic require- } \\
\text { ment time, } \min ^{c}\end{array}$ & $82 \pm 45$ & $132 \pm 60$ & $300 \pm 38$ & 0.000 \\
\hline $\begin{array}{l}\text { Total consumption of fen- } \\
\text { tanyl at first } 24 \text { hours, } \mu g^{b}\end{array}$ & $382 \pm 105$ & $352 \pm 98$ & $307 \pm 52$ & 0.001 \\
\hline Excellent satisfaction $^{\mathrm{d}}$ & $9(45)$ & $10(50)$ & $13(65)$ & 0.01 \\
\hline
\end{tabular}

\section{Discussion}

In this study, intra-articular administration of combined meperidine and bupivacaine at the end of knee arthroscopic surgery postponed the first postoperative analgesics request and reduced opioid consumption compared with each medication alone. Furthermore, the duration of postoperative analgesia was enhanced and the pain score at early postoperative period was diminished. These findings showed that combination of meperidine and bupivacaine might have supra-additive analgesic effects compared with each medication alone. To relieve pain after knee arthroscopy, a variety of techniques have been studied, among them epidural analgesia, femoral nerve blockade, intravenous patientcontrolled analgesia (PCA) and intra-articular injection can be mentioned (2, 4-7). Conducting each technique depends on various factors including experience and interest of the anesthesiologist and orthopedist, circumstances and facilities of hospital, costs of drugs and devices, etc. Intra-articular injection to the site of operation (knee) and no or minimal effects on other organs, brings about adequate analgesia and enables other or-

gans to have normal function and promotes patients' early ambulation. Accordingly, some studies with different efficiency have been conducted on intra-articular administration of drugs as time of injection (prior to or after operation), type of drug (local anesthetic, opioids, etc.) and volume of injectate (5 to $50 \mathrm{~mL}$ ) (16-23). Some reports revealed that intra-articular injection of bupivacaine brings about immediate but short-time analgesia. The analgesic effects of bupivacaine varied based on applied dosage and volume in different studies (9). Furthermore, opioids administration in intra-articular injection for pain relief is based on the hypothesis that "peripheral receptors of opioids are stimulated in response to occurrence of inflammation" (24). Furthermore, the volume of injectate may also have considerable effect on intra-articular opioid since increased intra-articular pressure can facilitate its systemic absorption and central manifestation of opioids (6). Studies conducted on intra-articular injection of morphine as sole analgesic, showed its mild analgesic effect (10). Rosseland et al. showed that $70 \%$ of their patients at first 
hour after knee arthroscopy had moderate to severe pain indicating poor analgesic effect of $2 \mathrm{mg}$ morphine in $10 \mathrm{~mL}$ normal saline (25). However, there are some studies in the favor of intraarticular effects of morphine compared with other opioids $(19,20)$. Opioids from phenylpiperidine group (such as meperidine, fentanyl and sufentanil) have been shown in laboratory studies to have local anesthetic effects (13). Nonetheless in human studies, meperidine is the sole opioid with weak local anesthetic effect administered in certain regional anesthetic techniques (e.g. spinal, epidural and caudal anesthesia as well as IVRA), which is a significant feature for meperidine among all opioids (13-15). However, following its widespread use, in recent years there were some concerns about its special hazards in systemic administration, which at least in part could enhance turning to intraarticular and other non-systemic routs of application (26-29). Compared with morphine, solubility of meperidine in fat tissue is higher, which advances its onset of action owing to its rapid absorption into blood circulation in the joint region with high flow of blood (30). Soderlund et al. studied intra-articular injection of meperidine with different doses $(50,100$ and 200 $\mathrm{mg}$ ) compared with prilocaine, before the arthroscopic knee surgery to provide surgical anaesthesia (31). They suggested that such doses of meperidine provided analgesia with both central and peripheral mechanisms; they showed that $50 \mathrm{mg}$ meperidine could not provide surgical anesthesia. In the other groups, local anesthesia was obtained, but 100 and $200 \mathrm{mg}$ meperidine caused unwanted adverse effects. In our study, the first analgesic requirement time in bupivacaine-meperidine mixture was significantly more than other groups and even the summation of other groups' times. Although VAS score between the groups was similar in late postoperative period probably due to PCA used by patients, in early period (2nd hour) that the fentanyl PCA was not used or did not reach enough plasma level, VAS scores were lower in BM group. This finding shows that when these two drugs administered together, a supra-additive analgesic effect was resulted. This mechanism could be somewhat resulted from weak local anesthetic property of meperidine compared to other opioids, and/or the result of meperidine effects on peripheral opioid receptors by blocking sodium channel. To date, only additive analgesic effect by intra-articular local anesthetics and opioids such as morphine has been observed. Therefore, this effect of meperidine and bupivacaine combination is an advantage over other opioids (e.g. morphine) or bupivacaine alone without any additional adverse effects. Main limitations of our study were limited number of participants, uni-center results, lack of laboratory assay to address the plasma level of medication and limiting the study to otherwise healthy patients who are more resistant to adverse effects. In conclusion, although postoperative intra-articular meperidine might be an appropriate alternative to bupivacaine, admin- istration of drugs together improved their effects and had a supra-additive effect compared with each medication alone.

\section{Acknowledgements}

Hereby we present our appreciation to all patients who generously helped us to perform this study, as well as the anesthesia staff nursery of operation room, orthopedic floor and pain department of Rasoul Medical Center, Iran University of Medical Sciences.

\section{Authors' Contributions}

Study design and data collection: Farnad Imani, Saeidreza Entezary, Mohammad Razi and Ali Akbar Jafarian. Analysis of data: Saeid Safari and Fardin Yousefshahi. Preparation, review and approval of the manuscript: Farnad Imani, Saeid Safari and Fardin Yousefshahi.

\section{References}

1. Edkin BS, Spindler KP, Flanagan JF. Femoral nerve block as an alternative to parenteral narcotics for pain control after anterior cruciate ligament reconstruction. Arthroscopy. 1995;11(4):404-9.

2. Wu CL, Bronstein RD, Chen JM, Lee DH, Rouse LM. Postoperative analgesic requirements in patients undergoing arthroscopic anterior cruciate ligament reconstruction. Am J Orthop (Belle Mead NJ). 2000;29(12):974-8.

3. Moghtadaei M, Farahini H, Faiz SHR, Mokarami F, Safari S. Pain Management for Total Knee Arthroplasty: Single-Injection Femoral Nerve Block versus Local Infiltration Analgesia. Iran Red Cres Med J. 2014;16(1).

4. Klasen JA, Opitz SA, Melzer C, Thiel A, Hempelmann G. Intraarticular, epidural, and intravenous analgesia after total knee arthroplasty. Acta Anaesthesiol Scand.1999;43(10):1021-6.

5. Mulroy MF, Larkin KL, Batra MS, Hodgson PS, Owens BD. Femoral nerve block with $0.25 \%$ or $0.5 \%$ bupivacaine improves postoperative analgesia following outpatient arthroscopic anterior cruciate ligament repair. Reg Anesth Pain Med. 2001;26(1):24-9.

6. Likar R, Kapral S, Steinkellner H, Stein C, Schafer M. Dose-dependency of intra-articular morphine analgesia. Br J Anaesth. 1999;83(2):241-4

7. Allen GC, St Amand MA, Lui AC, Johnson DH, Lindsay MP. Postarthroscopy analgesia with intraarticular bupivacaine/morphine. A randomized clinical trial. Anesthesiology.1993;79(3):475-80.

8. Soleimanpour H, Gahramani K, Taheri R, Golzari SE, Safari S, Esfanjani RM, et al. The effect of low-level laser therapy on knee osteoarthritis: prospective, descriptive study. Lasers in medical science. 2014

9. Moiniche S, Mikkelsen S, Wetterslev J, Dahl JB. A systematic review of intra-articular local anesthesia for postoperative pain relief after arthroscopic knee surgery. Reg Anesth Pain Med. 1999;24(5):430-7.

10. Gupta A, Bodin L, Holmstrom B, Berggren L. A systematic review of the peripheral analgesic effects of intraarticular morphine. Anesth Analg. 2001;93(3):761-70.

11. Francis PH. Respiratory depression after intra-articular morphine. Anaesth Intensive Care. 1999;27(6):669-70.

12. Amiri HR, Safari S, Makarem J, Rahimi M, Jahanshahi B. Comparison of combined femoral nerve block and spinal anesthesia with lumbar plexus block for postoperative analgesia in intertrochanteric fracture surgery. Anesthesiology and Pain Medicine. 2012;2(1):32-5.

13. Jaffe RA, Rowe MA. A comparison of the local anesthetic effects of meperidine, fentanyl, and sufentanil on dorsal root axons. Anesth Analg. 1996;83(4):776-81.

14. Ngan Kee WD. Intrathecal pethidine: pharmacology and clinical applications. Anaesth Intensive Care. 1998;26(2):137-46. 
15. Acalovschi I, Cristea T. Intravenous regional anesthesia with meperidine. Anesth Analg. 1995;81(3):539-43.

16. Denti M, Randelli P, Bigoni M, Vitale G, Marino MR, Fraschini N Pre- and postoperative intra-articular analgesia for arthroscopic surgery of the knee and arthroscopy-assisted anterior cruciate ligament reconstruction. A double-blind randomized, prospective study. Knee Surg Sports Traumatol Arthrosc. 1997;5(4):206-12.

17. Ekblom A, Westman L, Soderlund A, Valentin A, Eriksson E. Is intra-articular pethidine an alternative to local anaesthetics in arthroscopy? A double-blind study comparing prilocaine with pethidine. Knee Surg Sports Traumatol Arthrosc. 1993;1(3-4):189-94.

18. Huang GS, Yeh CC, Kong SS, Lin TC, Ho ST, Wong CS. Intra-articular ketamine for pain control following arthroscopic knee surgery. Acta Anaesthesiol Sin. 2000;38(3):131-6.

19. Arti H, Arti S. The Effects of Intraarticular Opioids in pain relief after Arthroscopic Menisectomy: A Randomized Clinical Trial Study. PakJ Med Sci. 2013;29(2):625-8.

20. Arti H, Mehdinasab SA. The comparison effects of intra-articular injection of different opioids on postoperative pain relieve after arthroscopic anterior cruciate ligament reconstruction: A randomized clinical trial study. J Res Med Sci. 2011;16(9):1176-82.

21. Jazayeri SM, Mosaffa F, Abbasian M, Hosseinzadeh HR. Comparing the efficacy of intra-articular application of morphine and tramadol on postoperative pain after arthroscopic knee surgery. Anesth Pain Med. 2012;2(1):28-31.

22. Sajedi P, Nemati M, Mosavi SH, Honarmand A, Safavi MR. A randomized controlled trial for the effectiveness of intraarticular versus intravenous midazolam on pain after knee arthroscopy. J Res Med Sci. 2014;19(5):439-44.

23. Chen DW, Hu CC, Chang YH, Lee MS, Chang CJ, Hsieh PH. Intraarticular bupivacaine reduces postoperative pain and meperi- dine use after total hip arthroplasty: a randomized, double-blind study. J Arthroplasty. 2014;29(12):2457-61.

24. Kalso E, Tramer MR, Carroll D, McQuay HJ, Moore RA. Pain relief from intra-articular morphine after knee surgery: a qualitative systematic review. Pain.1997;71(2):127-34.

25. Rosseland LA, Stubhaug A, Grevbo F, Reikeras O, Breivik H. Effective pain relief from intra-articular saline with or without morphine $2 \mathrm{mg}$ in patients with moderate-to-severe pain after knee arthroscopy: a randomized, double-blind controlled clinical study. Acta Anaesthesiol Scand. 2003;47(6):732-8.

26. Darvish H, Memar A. B, Mohammadkhani SS, Tajik A. Analgesic Efficacy of Diclofenac and Paracetamol vs. Meperidine in Cesarean Section. Anesth Pain Med. 2014;4(1).

27. Farzi F, Mirmansouri A, Forghanparast K, Heydarzadeh A, Abdollahzadeh M, Jahanyar Moghadam F. Addition of intrathecal fentanyl or meperidine to lidocaine and epinephrine for spinal anesthesia in elective cesarean delivery. Anesth Pain Med.2014;4(1).

28. Hendrickson RG, McKeown NJ. Is maternal opioid use hazardous to breast-fed infants? Clin Toxicol (Phila). 2012;50(1):1-14.

29. Yousefshahi F, Asadi M, Rahimi F, Hoseinzade MJ, Tanha FD, Barkhordari K, et al. The effect of meperidine on peripartum breastfeeding and neonatal weight. J Family Reprod Health. 2013;7(1):29-34.

30. Grass JA. Epidural analgesia. In: Fleisher LA, Prough DS, Grass JA editors. Problems in anesthesia.. Philadelphia: Lippincott-Raven; 1998. pp. 45-70.

31. Soderlund A, Boreus LO, Westman L, Engstrom B, Valentin A, Ekblom A. A comparison of 50,100 and $200 \mathrm{mg}$ of intra-articular pethidine during knee joint surgery, a controlled study with evidence for local demethylation to norpethidine. Pain. 1999;80(12):229-38. 